\title{
Aproximación cualitativa del escudriño en Psicología educativa
}

\section{Qualitative Approach of the Scrutiny in Educational Psychology}

\author{
Antonio Rodríguez Fuentes* \\ Universidad de Granada, Granada, España \\ ORCID: https://orcid.org/0000-0002-8036-9902 \\ María Jesús Caurcel Cara \\ Universidad de Granada, Granada, España \\ ORCID: https://orcid.org/0000-0002-2169-9100
}

Recibido 20-09-18 Revisado 09-10-18 Aprobado 12-01-19 En línea 20-03-19

\section{Correspondencia:}

Email: arfuentes@ugr.es

\section{Citar como:}

Rodríguez Fuentes, A., \& Caurcel Cara, M. (2019).

Aproximación cualitativa del escudriño en Psicología educativa. Propósitos y Representaciones, 7(1), 01-09. Doi: http://dx.doi.org/10.20511/pyr2019.v7n1.301

(C) Universidad San Ignacio de Loyola, Vicerrectorado de Investigación, 2019. 
El enfoque funcionalista ${ }^{1}$ tradicional en la representación y abordaje de la Ciencia ha dejado una férrea herencia metodológica de investigación de objetos y fenómenos objetivos con intención puramente nomotética de describirlos avanzado hacia principios y leyes generales, atemporales y universales, bajo métodos cuantitativos. Métodos cuantitativos tanto experimentales y/o cuasiexperimentales, de evaluación pretest-postest con un tratamiento intermedio, como no experimentales de tipo descriptivo, relacional, comparativo, predictivo, factorial y de metaanálisis, donde no existe manipulación o tratamiento por parte del investigador.

Mucho le costó al enfoque contrapuesto interpretativo ${ }^{2}$ combatir la anterior corriente exclusiva con su aproximación ideográfica al estudio de una realidad ahora subjetiva, que fueron consolidados y aplicados a la praxis con la intención transformadora del enfoque complementario socio-crítico $^{3}$. Y todo lo anterior mediante alguno de los métodos cualitativos: a) en el primer enfoque basados en la observación etnográfica participante o no participante, estudios de casos instrumentales, institucionales, individuales o colectivos, que proporcione la comprensión más que la descripción anterior; b) en el segundo mediante la investigación-acción o investigación basada en el diseño, que reviertan la situación estudiada para liberarla y mejorarla.

En enfrentamiento pluri-paragimático que incluso en la actualidad sigue vigente arrastró el enfrentamiento bi-metodológico, de tal manera que la dicotomía del investigador en su posicionamiento y planteamiento de todas las estructuras que le permiten acometer el proceso investigador se ha visto afectado por la tensión del binomio metodológico y sus propuestas metódicas de materialización. Pero ni la metodología pertenece a algún enfoque predeterminado ni los métodos a alguna de ellas. Ello atisba la única salida posible para que el proceso investigador resulte enriquecido del conflicto anterior.

En efecto, la superación del conflicto anterior ha sido resuelta mediante la complementariedad de paradigmas que logre una descripción más detallada de la realidad y de su forma de abordarla mediante la investigación. Incluso ha sido denominado como "paradigma emergente, integrador, holístico, comprensivo, ecológico o contextual” (Rodríguez, 2005, p. 109). En lugar de focalizar las diferencias y contrastes de cada uno de los anteriores, reconoce sus lagunas particulares y hasta sus críticas, pero de forma positiva y constructiva propone superarlas mediante un posicionamiento ecléctico, tomando lo mejor de cada uno.

Y respecto de la metodología, también se han propuesto métodos mixtos de investigación "MMR" (Cameron, 2001; Díaz, 2014). Se trata de la combinación metódica, empleando métodos de supuesta pertenencia tradicional a metodologías enfrentadas, o el empleo principal de un método pero albergando en su seno a otro método, incluso de supuestas metodologías diferentes. Es decir, un proceso investigador más abierto y dinámico donde lo importante es ofrecer la respuesta más completa y comprensiva al objetivo del estudio, lo que demanda en consecuencia un modelo y rol de investigador más flexible y versátil (Rodríguez, 2018), que en otro lugar (Rodríguez, 2017) se ha denominado metodología "cuantilativa", por su eclecticismo entre lo "cuantitativo" y la "cualitativo".

En el terreno específico de la Psicología de la Educación han predominado los esfuerzos de tipo cuantitativo y sus incuestionables métodos científicos, de ahí la crítica que han realizado algunos autores (Hernández, Fernández y Baptista, 2010) que han propuesto diversidad de métodos en el "abordaje de la investigación psicoeducativa" (De la Fuente y Justicia, 2018, p. 1), argumentando el objeto propio de la disciplina: la comprensión de cualquier fenómeno educativo, finalidad manifiestamente ideográfica más que nomotética. Así, como señala Sáenz (2007), no se puede obviar que se trata con seres humanos concretos, particulares, irrepetibles, que

\footnotetext{
${ }^{1}$ Positivista, técnico, burocrático, empírico, analítico, tecnológico, racional, eficientista, o combinación de los anteriores.

2 Simbólico, etnográfico, subjetivo, descriptivo, fenomenológico, antropológico, hermenéutico, o combinación de anteriores.

${ }^{3}$ Transformador, emancipador, social, crítico, estructuralista, humanista, o combinación de los anteriores.
} 
piensan y sienten, así como de grupos sociales y comunidades, contexto éste en el cual apelar a la investigación cualitativa permite ahondar en la interioridad, en lo subjetivo de esas personas y grupos; generando conocimiento sobre la realidad social, cultural y educativa desde el punto de vista de quienes la producen y viven (Balcázar, GonzálezArratia, Gurrola y Moysén, 2013).

El paradigma cualitativo enfatiza, en tal sentido, el contexto de descubrimiento, describe e interpreta los fenómenos de aprendizaje desde la perspectiva de los actores involucrados y la relación investigador-participante, buscando los significados y la comprensión de la realidad, atendiendo al contexto y a la cultura (Gonda, Ramírez y Zerpa, 2008). Así, ya no interesan los muestreos probabilísticos, la cantidad de los participantes y la representatividad de la muestra, sino las personas concretas cuyas características particulares les permitan participar en el estudio (Saénz, 2007). El investigador abandona la pasividad tradicional en pro de la "objetividad" y asume un papel activo constructivo-interpretativo y transformador de la realidad a lo largo de todo el proceso de la investigación y no sólo en algún momento de ella (Cuevas, 2002; Stake, 1998), constituyéndose en el instrumento principal de recolección y análisis de datos (Krause, 1995); y el investigado se constituye en agente productor de pensamiento y sentido (Cuevas, 2002) e igualmente transformador de la realidad.

En la Psicología Educativa de los últimos años la investigación cualitativa se encuentra en pleno desarrollo posicionándose como metodología válida y eficaz en la comprensión del fenómeno educativo (Hernández-Arteaga, 2012). Han aumentado notablemente los estudios con orientación cualitativa y los métodos alternativos de investigación que permiten comprender facetas y características novedosas de los conceptos y procesos psicoeducativos estudiados tradicionalmente (Gonda et al., 2008; Justicia y Pichardo, 2007). Estos estudios se basan en la flexibilidad y se desarrollan en el ambiente real del centro educativo y de las aulas, analizando los procesos de interacción docente-alumnado, alumno-alumno, contexto escolar-maestroalumnado, contexto familiar-social-escolar, etc., evaluando el proceso de enseñanza-aprendizaje desde la perspectiva subjetiva de los implicados y proporcionando avances en la comprensión teórica e interpretación de diversos aspectos organizacionales, instruccionales, sociales y emocionales del aula. Y para esta construcción del conocimiento utilizan una multiplicidad de métodos, medios, técnicas e instrumentos para investigar, tales como: la observación participante, la entrevista semiestructurada o abierta en profundidad, los grupos focales o de discusión, el análisis de contenido de naturaleza estructural o hermenéutico, la etnografía, las técnicas psicodramáticas y sociodramáticas, el estudio de casos, la inspección de historias de vida, los talleres, los diarios de campo, la evaluación de experiencias personales, la interacción en grupos o comunidades, la introspección, los cuadernos de campo, el portafolios, los registros anecdóticos, etc. (Balcázar et al, 2013; Delgado y Gutiérrez, 1999; Hernández et al., 2010; López-Pastor, 2009; Ruiz, 1999; Mejía, 2004; Taylor y Bogdan, 2002; Valles, 2003).

Llevar a cabo este tipo de investigación requiere, como refiere Hernández-Arteaga (2012), de competencia investigadora, apertura mental, conceptual, social, y tiempo para vincularse y participar de manera decidida e intensa en el contexto social objeto de estudio y cuidando el significado que los eventos tienen para los participantes de dicho contexto. Y, adicionalmente, un marco interpretativo que permita la determinación de la realidad del fenómeno social.

Las últimas tendencias en la investigación cualitativa desarrollada por los psicólogos educativos se caracteriza por utilizar la inter y transdisciplinariedad en el abordaje de problemas educativos, y en muchas ocasiones, en la búsqueda soluciones articulan estrategias cualitativas y cuantitativas en sus diseños. Lo que está en juego es la riqueza de la información recopilada y las derivaciones de la misma mediante distintos instrumentos de recogida de datos y análisis de los 
mismos para establecer resultados y conclusiones, que respondan a objetivos de estudios más reales y sincrónicos con los fenómenos que mezclan la psicología y la educación. Ánimo a investigadores con los esfuerzos de interpretación y transformación de la realidad psicoeducativa.

\section{Referencias}

Balcázar, P., González-Arratia, N. I., Gurrola, G. M., \& Moysén, A. (2013). Investigación cualitativa. México: Universidad Autónoma del Estado de México. Recuperado de http://hdl.handle.net/20.500.11799/21589

Cameron, R. (2011). Mixed Methods Research: The five Ps framework. The Electronic Journal of Business Research Methods, 9(2), 96-108. 2011. Recuperado de: http://www.ejbrm.com.

Cuevas, A. (2002). Consideraciones entorno a la investigación cualitativa en Psicología. Revista Cubana de Psicología, 19(1), 47-56. Recuperado de http://pepsic.bvsalud.org/pdf/rcp/v19n1/06.pdf

De la Fuente, J \& Justicia, F. (2018). Tópicos recientes de investigación en Psicología de la Educación. Madrid: EOS.

Delgado, J., \& Gutiérrez, J. (Eds.) (1999). Métodos y técnicas cualitativas de investigación en Ciencias Sociales ( $3^{\mathrm{a}}$ reimpresión). Madrid: Editorial Síntesis.

Díaz, S. M. (2014), Los métodos mixtos de investigación: presupuestos generales y aporte a la evaluación educativa. Revista Portuguesa de Pedagogía, 48(1), 7-23. 2014. Doi: http://dx.doi.org/10.14195/1647-8614_48-1_1

Gonda, S., Ramírez, J. J., \& Zerpa, C.E. (2008). Investigación cualitativa en Psicología Educativa: contribuciones al aprendizaje autorregulado. Laurus, Revista de Educación, 14(26), 111135. Recuperado de http://www.redalyc.org/articulo.oa?id=76111491006

Hernández, R., Fernández C., \& Baptista, P. (2010). Metodología de la investigación (5a ed.). México: McGraw Hill.

Hernández-Arteaga, I. (2012). Investigación cualitativa: una metodología en marcha sobre el hecho social. Revista Rastros Rostros, 14(27), 57-68. Recuperado de file:///C:/Users/maria/Downloads/Dialnet-InvestigacionCualitativa-6515553.pdf

Justicia, F., \& Pichardo, M.C. (2007). Metodología de Investigación en Psicología Evolutiva y de la Educación. En E. Fernández, F. Justicia y M.C. Pichardo, Enciclopedia de Psicología Evolutiva y de la Educación. (pp. 17-50). Málaga: Ediciones Aljibe.

Krause, M. (1995). La investigación cualitativa. Un campo de posibilidades y desafíos. Revista Temas de Educación, 7, 19-39.

López Pastor, V. (2009). Evaluación formativa y compartida en Educación Superior. Madrid: Nancea.

Mejía, J. (2004). Sobre la investigación cualitativa. Nuevos conceptos y campos de desarrollo. Investigaciones Sociales, 8(13), 277-299. Doi: http://dx.doi.org/10.15381/is.v8i13.6928

Rodríguez, A. (2005). Research on special education needs: what and how to investigate in special education. Electronic Journal of Research in Educational Psychology, 3(1), 97-112. Doi: http://dx.doi.org/10.25115/ejrep.v3i5.1158

Rodríguez, A. (2017). Proceso de investigación educativa: Metodología e informe de resultados. Curso desarrollado en el Instituto Panameño de Educación Especial, de la República de Panamá (Panamá). 5-9 de Junio de 2017.

Rodríguez, A. (2018). Investigación en educación. Conferencia impartida en el III Salón Estudiantil, organizada por la Unidad de Cultura Científica, del Vicerrectorado de Extensión Universitaria de la Universidad de Granada (España). 4 de Abril de 2018.

Ruiz, J. I. (1999). Metodología de la investigación cualitativa (2a edición). Bilbao: Universidad de Deusto.

Sáenz, M. A. (2007). Aproximación a la investigación cualitativa en Psicología y Educación. Revista Humanitas, 4(4), 58-81. Recuperado de http://132.248.9.34/hevila/HumanitasRevistadeinvestigacion/2007/vol4/no4/4.pdf

Stake, E. R. (1998). Investigación con estudio de casos. Madrid: Morata. 
Taylor, S. J., \& Bogdam, R. (2002). Introducción a los métodos cualitativos de investigación: La búsqueda de significados. Traducción de Jorge Piatigorsky. Barcelona: Ediciones Paidós Ibérica.

Valles, M. S. (2003). Técnicas cualitativas de investigación social: Reflexión metodológica y práctica profesional. Madrid: Editorial Síntesis. 